\title{
Procedural Competency Among Hospitalists: A Literature Review and Future Considerations
}

\author{
Joséphine A Cool, MD*, Grace C Huang, MD
}

Department of Medicine, Beth Israel Deaconess Medical Center, Boston, Massachusetts; Harvard Medical School, Boston, Massachusetts.

BACKGROUND: As general internists practicing in the inpatient setting, hospitalists at many institutions are expected to perform invasive bedside procedures, as defined by professional standards. In reality, hospitalists are doing fewer procedures and increasingly are referring to specialists, which threatens their ability to maintain procedural skills. The discrepancy between expectations and reality, especially when hospitalists may be fully credentialed to perform procedures, poses significant risks to patients because of morbidity and mortality associated with complications, some of which derive from practitioner inexperience.

METHODS: We performed a structured search of the peer-reviewed literature to identify articles focused on hospitalists performing procedures.

RESULTS: Our synthesis of the literature characterizes contributors to hospitalists' procedural competency and discusses: (1) temporal trends for procedures performed by hospitalists and their associated referral patterns, (2) data comparing use and clinical outcomes of procedures performed by hospitalists compared with specialists, (3) the lack of nationwide standardization of hospitalist procedural training and credentialing, and (4) the role of medical procedure services, although limited in supportive evidence, in concentrating procedural skill and mitigating risk in the hands of a few well-trained hospitalists.

CONCLUSION: We conclude with recommendations for hospital medicine groups to ensure the safety of hospitalized patients undergoing bedside procedures. Journal of Hospital Medicine 2021;16:230-235.

() 2021 Society of Hospital Medicine

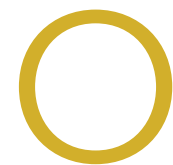

ver the past 20 years, hospitalists have served as the primary workforce for the clinical care of medical inpatients in the United States. ${ }^{1,2}$ Core competencies ${ }^{1}$ state that hospitalists should be able to perform the following bedside procedures: lumbar puncture, paracentesis, thoracentesis, arthrocentesis, and central venous catheter placement. More recently, standard of care has dictated that these procedures be performed under ultrasound guidance,,$^{3-6}$ and thus hospitalists are also expected to be adept at point-of-care ultrasound (POCUS).?

However, no current national standard exists for ensuring basic competency among hospitalists performing bedside procedures. In addition, hospitalists' procedural volumes are declining, ${ }^{8,9}$ and standards for procedural training during internal medicine residency have been reduced. ${ }^{10}$ As a result, many residents who intend to become hospitalists are no longer prepared to perform these procedures.

The ramifications of the loss of procedural competency for hospitalists are manifold. Technical errors are a significant source of patient morbidity and mortality, ${ }^{11-15}$ and complica-

*Corresponding Author: Joséphine A Cool, MD; Email: jcool@bidmc.harvard.edu. Published online first March 17, 2021.

Received: October 14, 2020; Revised: December 28, 2020;

Accepted: January 11, 2021

() 2021 Society of Hospital Medicine DOI 10.12788/jhm.3590 tions arising specifically from nonoperative procedures range from 0 to $19 \%,{ }^{16}$ although these data do not distinguish technical errors from unpreventable adverse events nor the degree to which hospitalists contributed to these complications. Second, hospitalists in academic medical centers might be ill equipped to function as supervisors of trainees performing procedures, which could perpetuate a cycle of suboptimal technical skills. ${ }^{17}$ Finally, the discrepancy between consensus guidelines for hospitalists and their scope of practice represents a significant area of risk management for institutions that base their credentialing policies on published competencies.

There are many compelling reasons for why hospitalists should maintain - in fact reclaim - a primary role in bedside procedures. ${ }^{18}$ Hospitalists in community and rural settings might not have easy access to procedural specialists. In academic institutions, hospitalists are the primary instructors and supervisors of procedures performed by internal medicine residents. The increased availability of POCUS allows formally trained hospitalists to perform procedures more safely under imaging guidance. ${ }^{16}$

The literature on procedures performed by hospitalists, although limited, has focused on POCUS, systems innovations such as medical procedure services (MPS), and policy recommendations for procedural credentialing. Most studies on effective procedural instructional approaches have been conducted among trainees, who are procedural novices. This research does not sufficiently address the dilemma that hospitalists face as 
independent physicians for whom procedures are not a significant component of their practice, yet are expected to perform invasive procedures occasionally. The purpose of our literature review is to synthesize the available research to characterize contributors to hospitalists' procedural competency. We conclude with considerations for hospital medicine practice.

\section{METHODS}

We performed a structured literature search for peer-reviewed articles related to hospitalists conducting procedures, being trained in procedures, or related to hospitalist-run MPS. We focused our search on the core hospitalist procedures with the highest potential morbidity (ie, lumbar puncture, abdominal paracentesis, thoracentesis, and central venous catheterization). We searched PubMed and Google Scholar for articles published since 1996 (when the term "hospitalists" was first coined) using keyword searches for [hospitalist OR hospital medicine] AND [procedur* OR medical procedur* OR medical procedure service] OR [(procedur* AND (train* OR educat* OR teach OR instruct $\left.\left.{ }^{\star}\right)\right]$ OR abdominal paracentes* OR thoracentes* OR lumbar puncture OR central venous catheter* OR ultrasound OR point-of-care. We included original research, brief research reports, perspectives, guidelines, and consensus statements. Exclusion criteria were articles that focused on nonhospitalists and conference abstracts. We used pearling to identify secondary sources from included articles' bibliographies, without limits on year of publication.

\section{RESULTS}

\section{Trends Towards Specialist Referrals}

Between 1986 and 2007, the number and variety of procedures performed by internists decreased by half. ${ }^{19}$ Hospitalists still completed procedures in greater volume and variety than nonhospitalists, ${ }^{8}$ with approximately $50 \%$ of hospitalists performing lumbar punctures (50\%), abdominal paracenteses (49\%), and thoracenteses (44\%) compared with less than $25 \%$ for all three procedures for nonhospitalists. Additionally, only $11 \%$ of surveyed hospitalists ${ }^{8}$ performed all nine core procedures, although these included procedures that are largely cognitive in nature (eg, electrocardiogram interpretation, chest X-ray interpretation) or procedures that have been relegated to other specialists (eg, endotracheal intubation, ventilator management, or joint injection/aspiration).

Surveys showed that, especially in larger cities and academic centers, procedural specialists have taken over a disproportionate share of procedures even as the number of procedures performed continued to rise. ${ }^{20}$ Between 1993 and 2008, the number of paracenteses and thoracenteses increased by $133 \%$ and decreased by $14 \%$, respectively, but the share of procedures performed by radiologists increased by $964 \%$ and $358 \%$, respectively, as evident in an analysis of Medicare billing data. ${ }^{20}$ A more recent study of Medicare claims from 2004 to 2016 similarly revealed that the percentage of paracenteses performed by radiologists compared with nonradiologists rose from $70 \%$ to $80 \%$ and thoracenteses from $47 \%$ to $66 \%$, respectively. ${ }^{21}$ Comparable trends were apparent in claims data for lumbar punctures; between 1991 and 2011, the share of lumbar punctures performed by radiologists rose from $11 \%$ to $48 \% .{ }^{22}$

In academic medical centers, hospitalists might have the opportunity to pursue other activities (eg, education, administration, research) as they progress in their careers, resulting in less clinical activity. Although hospitalists who are more clinically active in hospital care tended to perform more procedures, those with smaller clinical footprints reported lower levels of comfort with performing procedures ${ }^{8}$ and might have less available time to maintain procedural competency or train in new technologies such as POCUS. ${ }^{17}$

Additionally, hospitalists in both academic and community settings cited efficiency as a major reason for procedural referral. Hospitalists tended to perform more procedures if they had fixed salaries or if less than $50 \%$ of their income was based on clinical productivity, although this trend was not significant. ${ }^{8}$ Further, they also might be motivated by competing opportunity costs such as time lost caring for other patients or length of shift, which influences the amount of time spent at work. ${ }^{23}$

Notably, speculation that hospitalists referred more complex cases to specialists was not borne out by studies examining referral patterns. ${ }^{21,24,25}$

\section{Procedural Outcomes for Hospitalists vs Nonhospitalists}

No convincing data exist that procedures performed by specialists have better outcomes than those completed at the bedside by well-trained generalists, although studies were limited to the inpatient setting, to generalists who have some exposure to procedures, and to internal medicine residents on inpatient rotations. In one retrospective review, interventional radiology (IR) referrals were associated with more platelet or plasma transfusions and intensive care unit transfers than those performed at the bedside by internal medicine residents, findings that remained significant after accounting for complexity (eg, Model for End-stage Liver Disease score, need for dialysis, and platelet count). ${ }^{24}$ Similarly, a prospective audit of 529 bedside procedures did not show any differences in complication rates between generalists and pulmonologists, once generalists underwent standardized training and used pleural safety checklists and ultrasound guidance. ${ }^{26}$ An administrative database review of 130,000 inpatient thoracenteses across several university hospitals between 2010 and 2013 found that the risk of iatrogenic pneumothorax was similar among operators from IR, medicine, and pulmonary $(2.8 \%, 2.9 \% \text {, and } 3.1 \% \text {, respectively })^{27}$; these findings have been reproduced in other studies. ${ }^{28}$ Finally, the increasing adoption of procedural ultrasound permits procedures to be conducted more safely at the bedside, without the need to refer to radiology for imaging guidance. ${ }^{3-5}$

IR procedures also are associated with increased healthcare costs compared with bedside procedures. One study showed that hospital costs for admissions when paracenteses were performed by radiologists were higher than those in which the procedure was completed at the bedside by gastroenterologists or hepatologists. ${ }^{25} \mathrm{~A}$ chart review examining 399 paracenteses, thoracenteses, and lumbar punctures found 
that the average procedure cost increased by $38 \%$ for referred procedures and $56 \%$ for radiology-performed procedures, as compared with bedside procedures. ${ }^{29}$ Needing ancillary staffing in dedicated suites to perform procedures contributed to the excess cost. ${ }^{9}$ Moreover, referred procedures resulted in increased length of stay, which can incur additional costs. However, the data were conflicting; two studies did not show a statistical difference, ${ }^{25,28}$ while others found an increased length of stay, $^{24,27,29}$ which might be due to the unavailability of specialists during off hours, thereby delaying nonemergent procedures. ${ }^{21}$ Detailed cost analyses have controlled for the use of procedural facilities and blood transfusions among IR specialists and simulation training among generalists, showing that total costs were $\$ 663$ per patient undergoing IR procedures compared with $\$ 134$ per patient undergoing bedside procedures. ${ }^{30}$

\section{Lack of Standardized Procedural Training or Assessment}

A robust body of primary studies and systematic reviews supports the use of simulation for procedural training to improve comfort and skill as well as reduce complication rates and costs. ${ }^{31,32}$ A systematic review that investigated the impact of four paradigms of procedural training found that MPS and quality improvement/patient safety approaches led to the most active learning compared with apprenticeship (ie, "see one, do one") and approaches based on educational theories. ${ }^{33}$ Nevertheless, the vast majority of the research has been conducted in trainees, ${ }^{32,34}$ with sparse evidence among practicing physicians. One cohort study of attending physicians' central venous catheter insertion skills on simulators found low and variable short-term performance, showing overall poor adherence to checklists. ${ }^{35}$ One article suggested that hospitalists' procedural skills were below established thresholds of competency at baseline and that simulation-based training did not result in sustained skills, but the small sample size and high attrition limited meaningful conclusions. ${ }^{36}$ Although continuing medical education courses are available to hospitalists, there is no published evidence supporting their effectiveness.

Proxies for procedural skill have included comfort and experience, yet these markers have broadly been shown to be inadequate. ${ }^{34,36,37}$ Additionally, the natural decline of skill over time has invoked the need for periodic reassessment of proficiency. ${ }^{36,38}$ Credentialing has been equally inconstant; a survey of the Society of Hospital Medicine's (SHM) POCUS task force revealed that only half of respondents reported their hospitals required a minimum number of procedures for initial credentialing and recredentialing. ${ }^{39}$ In short, periodic assessment of procedural skills among hospitalists has not been a routine process at many institutions.

\section{Role of Hospitalist-Run Medical Procedure Services}

It might not be necessary for all hospitalists to be proficient and credentialed in a given procedure, ${ }^{1}$ and a trend has emerged in the creation of MPS staffed by hospitalists as proceduralists. The primary aim of these MPS has been to recapture the procedures-and associated revenue-that would otherwise be referred to specialists. Moreover, concentrating procedures among a core group of hospitalists endeavors to support patient safety through several principles: (1) to increase technical proficiency through higher procedural volumes, (2) to facilitate rigorous training and assessment among dedicated individuals, and (3) to systematize best practices of operator performance, communication, and documentation.

MPS have been implemented around the country and have demonstrated several advantages. In one institution, medical firms that were offered the use of an MPS had $48 \%$ more procedural attempts by nonspecialists, without significant differences in the proportions of successful attempts or complications compared with the firms who more often referred to specialists. ${ }^{40} \mathrm{~A}$ retrospective study analyzed outcomes of 1,707 bedside procedures, of which 548 were performed by an MPS, and found that procedures done by the MPS were more likely to result in lower rates of unsuccessful procedures and to use best-practice safety processes (ie, to involve attending physicians, to use ultrasound guidance, and to avoid femoral sites for catheterization). ${ }^{12}$ Satisfaction was high among patients who underwent bedside procedures performed by a hospitalist-supervised, intern-based procedure service with a focus on bedside communication. ${ }^{41}$ From a workforce perspective, MPS have also allowed surgical or radiological subspecialties to focus on more complex cases with higher reimbursement rates, ${ }^{18,42}$ for proceduralists to expand beyond core procedures (eg, bone marrow biopsies $\left.{ }^{43}\right)$, and to train advanced practice providers. ${ }^{44}$ Although studies have not shown that the outcomes of procedures completed by an MPS are better than the outcomes of procedures performed by other specialists, ${ }^{45}$ one can potentially extrapolate from earlier data that procedures done at the bedside by nonradiologists would have comparable outcomes.

\section{DISCUSSION}

A myriad of factors is influencing hospitalists' scope of practice with respect to bedside procedures. Some evidence suggests that procedures performed by specialists are not superior to those done by generalists and might be associated with increased costs. The most promising developments in the past few decades include simulation-based training, which has demonstrated effectiveness across an array of clinical outcomes but has not been sufficiently evaluated in hospitalists to draw conclusions, and hospitalist-led MPS, which promote safe and productive procedural clinical practices. However, decreasing procedural volume, increasing referrals to specialists, dwindling hospitalist interest and/or confidence, time constraints, limited training opportunities, nonuniform credentialing policies, and lack of standardized assessment are cumulatively contributing to a loss of procedural competency among hospitalists.

Taken together, these forces should compel hospital medicine groups that expect their hospitalists to perform their own procedures to identify necessary steps for ensuring the safety of hospitalized patients under their care. The following considerations derive from the available-albeit modest-evidence on procedural performance in hospital medicine (Table). 
TABLE. Recommendations to Optimize Procedural Competency Among Hospitalists

\begin{tabular}{|c|c|c|}
\hline Recommendation & Supportive principles & Challenges to address \\
\hline $\begin{array}{l}\text { Create medical procedure services to train and maintain a core } \\
\text { set of hospitalists to carry out procedures }\end{array}$ & $\begin{array}{l}\text { - Concentrates training efforts on motivated and skilled } \\
\text { hospitalists } \\
\text { - Could improve clinical outcomes } \\
\text { - Might recoup costs lost to other specialists }\end{array}$ & $\begin{array}{l}\text { Requires departmental investment for training, assessment, } \\
\text { full-time equivalent allocation, bedside ultrasounds, and } \\
\text { administrative support }\end{array}$ \\
\hline $\begin{array}{l}\text { Collaborate with procedural specialists to arrange coverage } \\
\text { during off hours and delineate thresholds for procedures that } \\
\text { specialists should perform }\end{array}$ & $\begin{array}{l}\text { Distribution of "routine" procedures to hospitalists reduces } \\
\text { the burden on specialists }\end{array}$ & $\begin{array}{l}\text { - Specialists may be unwilling to participate in 24-hour/7-day- } \\
\text { a-week coverage }\end{array}$ \\
\hline Collaborate with residency programs to train interested residents & $\begin{array}{l}\text { - Procedural training needs are similar between residents and } \\
\text { hospitalists and offer economies of scale in financial costs } \\
\text { - Establishing procedural skill is mutually beneficial to trainees } \\
\text { performing procedures and hospitalists supervising them }\end{array}$ & $\begin{array}{l}\text { - Sharing investment in equipment and resources requires } \\
\text { institutional buy-in } \\
\text { - Involving residents in medical procedure services might } \\
\text { decrease its efficiency }\end{array}$ \\
\hline $\begin{array}{l}\text { Revise credentialing and privileging processes for procedural } \\
\text { competency }\end{array}$ & - Current processes may lack verification of actual proficiency & $\begin{array}{l}\text { - Scrutiny of policies signals a commitment to formal } \\
\text { documentation of hospitalists' procedure skills, which might } \\
\text { require groups to provide training and/or remediation }\end{array}$ \\
\hline
\end{tabular}

1. Create MPS to establish a core set of hospitalists to perform procedures and train them using evidence-based practices. Creation of an MPS places the responsibility of core bedside procedures in the hands of a select group of proceduralists. This strategy streamlines training and assessment of individual procedural competency to meet standards set by $\mathrm{SHM}^{36,46}$ and improves educational outcomes. ${ }^{47-49}$ MPS could improve clinical outcomes, ${ }^{12,42,50-52}$ including length of stay and cost, while maintaining patient satisfaction, ${ }^{41}$ as well as recoup lost revenue from referrals by increasing the volume of procedures done by generalists, ${ }^{40,49}$ although no robust data supporting the latter point exists. Implementing an MPS requires full-time equivalent (FTE) support for proceduralists and administrative support for data collection and tracking complications. Furthermore, a well-functioning MPS will require investment in portable ultrasound machines and training in POCUS, which has been shown to decrease complications and increase success of invasive bedside procedures. $^{3-7}$ Hospital medicine groups should be aware that staffing an MPS can divert hospitalist labor and resources from other needed clinical areas, especially during the initial, low-volume phases of implementation. Strategies to offset relative value unit (RVU) loss include combining the MPS with existing clinical roles such as medical consults, code triage, and rapid response teams; or with services with lower patient caps, which might work particularly well in community hospitals. In many institutions, hospitalists can bill for procedural consults in addition to the procedures when the consult involves nonmedical patients, which is relevant when the procedure ultimately cannot be performed (eg, too little ascites to safely perform a paracentesis). Further research should establish best practices of MPS to ensure maximum procedural productivity and safety, because there are no rigorous prospective studies that evaluate strategies to create this service. Such strategies include determining the optimal ratio of proceduralists to general hospitalists, hospital characteristics that benefit most from MPS (eg, referral centers, urban-based settings), volume and type of procedures performed, and the proportion and type of referrals that are most cost-effective.

2. Establish policies with procedural specialists to arrange coverage for off-hours procedures and delineate thresholds for procedures that specialists should perform. Expanding hospitalists' capabilities in performing procedures should trigger reconsideration of the medical center's approach to procedural safety. A goal would be to have hospital medicine groups work collaboratively with specialists and other disciplines (eg, surgery, emergency medicine, anesthesia, or radiology) to ensure 24-hour, 7-day a week coverage of urgent bedside procedures. The potential to decrease length of stay and improve off-hour procedural quality might be a compelling rationale for hospital administration, whether or not an MPS is used. That said, we recognize that other services might be unable or unwilling to provide such coverage and that specialist off-hour coverage would incur increased costs and could reduce exposure opportunities for internal medicine residents.

A hospital-level procedures committee might be required to support an institutional imperative for procedural safety and to oversee the implementation of approaches that are practical, financially sustainable, and equitable for all service lines, especially because hospitalist groups might bear the early costs of training and retraining.

3. Hospitalist-proceduralists should collaborate with internal medicine residency programs to offer intensive procedural training experiences to residents who want these skills to be part of their future practice.

Robust procedural training for trainees promotes better outcomes for the current workforce and helps to populate the future workforce with procedurally competent practitioners. Simulation-based training is a well-established procedural instruction method that is safe, authentic, and effective in terms of clinical outcomes. ${ }^{34}$ As the primary teachers of residents in many institutions, hospitalists often are the ones who impart procedur- 
al skills to residents, despite uneven skill sets. It is in the interest of internal medicine residency program directors to advocate for a core group of hospitalist-proceduralists, as MPS offer an infrastructure for training that has been shown to increase procedural volume and improve skills. ${ }^{47,48,50}$ Program directors could therefore be incentivized to sponsor some of these procedural roles with teaching and administration funds, as a trade-off for securing higher-quality procedural training and closer supervision for their trainees. The dual necessity of teaching procedural skills to residents and attending physicians alike offers economies of scale for the use of facilities, personnel, and equipment, and gives faculty an opportunity to extend their clinical teaching skills into the domain of procedural supervision.

\section{Hospital medicine groups should re-evaluate credential-} ing and privileging to ensure procedural competency. Given the lack of published data that characterizes how many hospital medicine groups credential hospitalists to perform procedures and what practices they use to assess competency, hospital medicine groups might be signing off on procedures without verifying hospitalists' proficiency in core procedures. SHM's position statement on credentialing for ultrasoundguided procedures ${ }^{46}$ describes standards that could be applied to other procedures. It proposes that credentialing processes should be grounded in simulation- and patient-based assessments of cognitive and psychomotor skills, using published checklists and global ratings for feedback. Simulation training could support provisional certification, but hospitalists should reach minimum thresholds of supervised patient-based experience before initial credentialing, with continuous reassessment of competency to mitigate skill decay. Prospectively tracking procedural metrics, such as procedural volume and complication rates, also will support systematic skill assessment. Finally, similar to any other medical error, near misses and complications should trigger periprocedural safety reviews.

\section{Limitations}

The modest body of research on hospitalists and procedures is the central limitation of our synthesis. Much of the literature consisted of consensus statements, retrospective studies, and small prospective educational studies. As a result, we did not adopt all strategies considered standard in a scoping or systematic review. The literature on MPS specifically was insufficient to draw conclusions about their operational and financial impact or effects on procedure quality. Our primary recommendation to implement MPS requires significant fiscal investment and infrastructure. It also entails risks that must be proactively addressed, including the potential for net financial loss and decreased educational opportunities for residents.

\section{CONCLUSIONS}

Hospitalists regularly face the predicament of being expected to independently perform procedures, with little access to training, minimal experience, and no ongoing assessment to ensure their proficiency or the safety of their patients. Past assumptions about hospitalists' responsibility do not reflect reali- ties in practice patterns and have not translated to widespread adoption of procedural training, monitoring, and assessment mechanisms. Our work summarizes a body of literature that, although limited in empiric studies of hospitalists themselves, offers insights with recommendations for hospital medicine groups wishing to uphold procedural skills as part of their providers' professional identity.

Disclosures: The authors have nothing to disclose.

\section{References}

1. Dressler DD, Pistoria MJ, Budnitz TL, McKean SCW, Amin AN. Core competencies in hospital medicine: Development and methodology. J Hosp Med. 2006;1(1):48-56. https://doi.org/10.1002/jhm.6

2. Wachter RM, Goldman L. Zero to 50,000 - The 20th anniversary of the hospitalist. N Engl J Med. 2016;375(11):1009-1011. https://doi.org/10.1056 /NEJMp1607958

3. Cho J, Jensen TP, Reierson K, et al. Recommendations on the use of ultrasound guidance for adult abdominal paracentesis: a position statement of the Society of Hospital Medicine. J Hosp Med. 2019;14:E7-E15. https:// doi.org/10.12788/jhm.3095

4. Soni NJ, Franco-Sadud R, Kobaidze K, et al. Recommendations on the use of ultrasound guidance for adult lumbar puncture: a position statement of the Society of Hospital Medicine. J Hosp Med. 2019;14(10):591-601. https:// doi.org/10.12788/jhm.3197

5. Dancel R, Schnobrich D, Puri N, et al. Recommendations on the use of ultrasound guidance for adult thoracentesis: a position statement of the Society of Hospital Medicine. J Hosp Med. 2018;13(2):126-135. https://doi.org/10.12788 /jhm.2940

6. Franco-Sadud R, Schnobrich D, Mathews BK, et al. Recommendations on the use of ultrasound guidance for central and peripheral vascular access in adults: a position statement of the Society of Hospital Medicine. J Hosp Med. 2019;14:E1-E22. https://doi.org/10.12788/jhm.3287

7. Soni NJ, Schnobrich D, Mathews BK, et al. Point-of-care ultrasound for hospitalists: a position statement of the Society of Hospital Medicine. J Hosp Med. 2019;14:E1-E6. https://doi.org/10.12788/jhm.3079

8. Thakkar R, Wright SM, Alguire P, Wigton RS, Boonyasai RT. Procedures performed by hospitalist and non-hospitalist general internists. J Gen Intern Med. 2010;25(5):448-452. https://doi.org/10.1007/s11606-010-1284-2

9. Lucas BP, Asbury JK, Franco-Sadud R. Training future hospitalists with simulators: a needed step toward accessible, expertly performed bedside procedures. J Hosp Med. 2009;4(7):395-396. https://doi.org/10.1002/jhm.602

10. American Board of Internal Medicine. Policies and procedures for certification. Accessed December 3, 2020. https://www.abim.org/ /media/ABIM\%20 Public/Files/pdf/publications/certification-guides/policies-and-procedures. pdf

11. MyersLC. Towardpreventingmedicalmalpracticeclaims relatedtochestprocedures. AnnAm ThoracSoc. 2020;17(6):776-779. https://doi.org/10.1513/Annals ATS.201912-863RL

12. Tukey MH, Wiener RS. The impact of a medical procedure service on patient safety, procedure quality and resident training opportunities. J Gen Intern Med. 2014;29(3):485-490. https://doi.org/10.1007/s11606-013-2709-5

13. Brennan TA, Leape LL, Laird NM, et al. Incidence of adverse events and negligence in hospitalized patients. N Engl J Med. 1991;324(6):370-376. https:// doi.org/10.1056/NEJM199102073240604

14. Leape LL, Brennan TA, Laird N, et al. The nature of adverse events in hospitalized patients. N Engl J Med. 1991;324(6):377-384. https://doi.org/10.1056 /NEJM199102073240605

15. Myers LC, Gartland RM, Skillings J, et al. An examination of medical malpractice claims involving physician trainees. Acad Med. 2020;95(8):1215-1222. https://doi.org/10.1097/ACM.0000000000003117

16. Mercaldi CJ, Lanes SF. Ultrasound guidance decreases complications and improves the cost of care among patients undergoing thoracentesis and paracentesis. Chest. 2013;143(2):532-538. https://doi.org/10.1378 /chest.12-0447

17. Vaisman A, Cram P. Procedural competence among faculty in academic health centers: challenges and future directions. Acad Med. 2017;92(1): 31-34. https://doi.org/10.1097/ACM.0000000000001327

18. Nelson B. Hospitalists try to reclaim lead role in bedside procedures. The 
Hospitalist. March 2015. Accessed June 27, 2020. https://www.the-hospitalist .org/hospitalist/article/122571/hospitalists-try-reclaim-lead-role-bedside -procedures

19. Wigton RS, Alguire P; American College of Physicians. The declining number and variety of procedures done by general internists: a resurvey of members of the American College of Physicians. Ann Intern Med. 2007;146(5):355-360. https://doi.org/10.7326/0003-4819-146-5-200703060-00007

20. Duszak R Jr, Chatterjee AR, Schneider DA. National fluid shifts: fifteen-year trends in paracentesis and thoracentesis procedures. J Am Coll Radiol. 2010;7(11):859-864. https://doi.org/10.1016/j.jacr.2010.04.013

21. Gottumukkala RV, Prabhakar AM, Hemingway J, Hughes DR, Duszak R Jr. Disparities over time in volume, day of the week, and patient complexity between paracentesis and thoracentesis procedures performed by radiologists versus those performed by nonradiologists. J Vasc Interv Radiol 2019;30(11):1769-1778.e1. https://doi.org/10.1016/j.jvir.2019.04.015

22. Kroll H, Duszak R Jr, Nsiah E, Hughes DR, Sumer S, Wintermark M. Trends in lumbar puncture over 2 decades: a dramatic shift to radiology. Am J Roentgenol. 2014;204(1):15-19. https://doi.org/10.2214/AJR.14.12622

23. Jensen T, Lai A, Mourad M. Can lessons from systems-based mastery learning for thoracentesis be translated to hospitalists? J Hosp Med. 2016;11(11): 811-812. https://doi.org/10.1002/jhm.2655

24. Barsuk JH, Cohen ER, Feinglass J, McGaghie WC, Wayne DB. Clinical outcomes after bedside and interventional radiology paracentesis procedures. Am J Med. 2013;126(4):349-356. https://doi.org/10.1016/ j.amjmed.2012.09.016

25. Barsuk JH, Feinglass J, Kozmic SE, Hohmann SF, Ganger D, Wayne DB. Specialties performing paracentesis procedures at university hospitals: implications for training and certification. J Hosp Med. 2014;9(3):162-168. https:// doi.org/10.1002/jhm.2153

26. See KC, Ong V, Teoh CM, et al. Bedside pleural procedures by pulmonologists and non-pulmonologists: a 3-year safety audit. Respirology. 2014;19(3):396-402. https://doi.org/10.1111/resp.12244

27. Kozmic SE, Wayne DB, Feinglass J, Hohmann SF, Barsuk JH. Factors associated with inpatient thoracentesis procedure quality at university hospitals. Jt Comm J Qual Patient Saf. 2016;42(1):34-40. https://doi.org/10.1016/S1553 -7250(16)42004-0

28. Berger MS, Divilov V, Paredes H, Sun E. Abdominal paracentesis: safety and efficacy comparing medicine resident bedside paracentesis vs. paracentesis performed by interventional radiology. J Clin Gastroenterol Hepatol. 2018:2(4). https://doi.org/10.21767/2575-7733.1000050

29. Kay C, Wozniak EM, Szabo A, Jackson JL. Examining invasive bedside procedure performance at an academic medical center. South Med J. 2016;109(7):402-407. https://doi.org/10.14423/SMJ.0000000000000485

30. Barsuk JH, Cohen ER, Feinglass J, et al. Cost savings of performing paracentesis procedures at the bedside after simulation-based education. Simul Healthc. 2014;9(5):312-318. https://doi.org/10.1097/SIH.0000000000000040

31. Barsuk JH, Cohen ER, Williams MV, et al. Simulation-based mastery learning for thoracentesis skills improves patient outcomes: a randomized trial. Acad Med. 2018;93(5):729-735. https://doi.org/10.1097/ACM.0000000000001965

32. Huang GC, McSparron JI, Balk EM, et al. Procedural instruction in invasive bedside procedures: a systematic review and meta-analysis of effective teaching approaches. BMJ Qual Saf. 2016;25(4):281-294. https://doi.org/10.1136 /bmjas-2014-003518

33. Brydges R, Stroud L, Wong BM, Holmboe ES, Imrie K, Hatala R. Core competencies or a competent core? a scoping review and realist synthesis of invasive bedside procedural skills training in internal medicine. Acad Med. 2017:92(11):1632-1643. https://doi.org/10.1097/ACM.0000000000001726

34. Brydges R, Hatala R, Zendejas B, Erwin PJ, Cook DA. Linking simulation-based educational assessments and patient-related outcomes: a systematic review and meta-analysis. Acad Med. 2015;90(2):246-256. https:// doi.org/10.1097/ACM.0000000000000549

35. Barsuk JH, Cohen ER, Nguyen D, et al. Attending physician adherence to a 29-component central venous catheter bundle checklist during simulated procedures. Crit Care Med. 2016;44(10):1871-1881. https://doi.org/10.1097 /CCM.0000000000001831

36. Crocker JT, Hale CP, Vanka A, Ricotta DN, McSparron JI, Huang GC. Raising the bar for procedural competency among hospitalists. Ann Intern Med. 2019;170(9):654-655. https://doi.org/10.7326/M18-3007

37. Barsuk JH, Cohen ER, Feinglass J, McGaghie WC, Wayne DB. Residents' procedural experience does not ensure competence: a research synthesis. J Grad Med Educ. 2017;9(2):201-208. https://doi.org/10.4300 /JGME-D-16-00426.1

38. Sawyer T, White M, Zaveri $P$, et al. Learn, see, practice, prove, do, maintain: an evidence-based pedagogical framework for procedural skill training in medicine. Acad Med. 2015;90(8):1025-1033. https://doi.org/10.1097 /ACM.0000000000000734

39. Jensen T, Soni N, Tierney D, Lucas B. Hospital privileging practices for bedside procedures: a survey of hospitalist experts. J Hosp Med. 2017;12(10): 836-839. https://doi.org/10.12788/jhm.2837

40. Lucas BP, Asbury JK, Wang Y, et al. Impact of a bedside procedure service on general medicine inpatients: a firm-based trial. J Hosp Med. 2007;2(3): 143-149. https://doi.org/10.1002/jhm.159

41. Mourad M, Auerbach AD, Maselli J, Sliwka D. Patient satisfaction with a hospitalist procedure service: Is bedside procedure teaching reassuring to patients? J Hosp Med. 2011;6(4):219-224. https://doi.org/10.1002/jhm.856

42. Ault MJ, Rosen BT. Proceduralists - leading patient-safety initiatives. N Engl J Med. 2007;356(17):1789-1790. https://doi.org/10.1056/NEJMc063239

43. Obasi JU, Umpierrez De Reguero AP. Safety profile of bone marrow aspiration and biopsies performed by the hospitalist procedure service at an academic center: an observational study. Blood. 2019;134(suppl 1): 5848. https:// doi.org/10.1182/blood-2019-121444

44. Gisondi MA, Regan L, Branzetti J, Hopson LR. More learners, finite resources, and the changing landscape of procedural training at the bedside. Acad Med. 2018;93(5):699-704. https://doi.org/10.1097/ACM.0000000000002062

45. McCormack J. The new proceduralists: Have they found their niche? American Medical News. September 17, 2007. Accessed August 30, 2020. https:// amednews.com/article/20070917/business/309179994/4/

46. Lucas BP, Tierney DM, Jensen TP, et al; Society of Hospital Medicine Point-ofCare Ultrasound Task Force. Credentialing of hospitalists in ultrasound-guided bedside procedures: a position statement of the Society of Hospital Medicine. J Hosp Med. 2018;13(2):117-125. https://doi.org/10.12788/jhm.2917

47. Lenhard A, Moallem M, Marrie RA, Becker J, Garland A. An intervention to improve procedure education for internal medicine residents. J Gen Intern Med. 2008;23(3):288-293. https://doi.org/10.1007/s11606-008-0513-4

48. Mourad M, Ranji S, Sliwka D. A randomized controlled trial of the impact of a teaching procedure service on the training of internal medicine residents. J Grad Med Educ. 2012;4(2):170-175. https://doi.org/10.4300 /JGME-D-11-00136.1

49. Montuno A, Hunt BR, Lee MM. Potential impact of a bedside procedure service on training procedurally competent hospitalists in a community-based residency program. J Community Hosp Intern Med Perspect. 2016;6(3):31054. https://doi.org/10.3402/jchimp.v6.31054

50. Smith CC, Gordon CE, Feller-Kopman D, et al. Creation of an innovative inpatient medical procedure service and a method to evaluate house staff competency. J Gen Intern Med. 2004;19(5p2):510-513. https://doi.org/10.1111/j.1525 $-1497.2004 .30161 . x$

51. Mourad M. Capsule commentary on Tukeyetal., the impact of a medical procedure service on patient safety, procedure quality and resident training opportunities. J Gen Intern Med. 2014;29(3):518. https://doi.org/10.1007/s11606-013 $-2740-6$

52. Halm EA, Lee C, Chassin MR. Is volume related to outcome in health care: a systematic review and methodologic critique of the literature. 2002. Database of Abstracts of Reviews of Effects (DARE): Quality-assessed Reviews Accessed June 26, 2020. https://www.ncbi.nlm.nih.gov/books/NBK69189/ 